\title{
Modified sulfonation method for converting carbonized glucose into solid acid catalyst for the esterification of palm fatty acid distillate
}

\begin{abstract}
The sulfonation variables for the preparation of a sulfonated incomplete carbonized glucose solid acid catalyst were optimized using response surface methodology (RSM) with central composite rotatable design for the conversion of palm fatty acid distillate (PFAD) to fatty acid methyl esters (FAME). Effects of four sulfonation variables namely time (1-9 h), (NH4)2SO4 concentration (2-18\%), concentrated $\mathrm{H} 2 \mathrm{SO} 4(15-35 \mathrm{ml})$ and temperature $\left(130-170{ }^{\circ} \mathrm{C}\right)$ were investigated. The optimum sulfonation conditions generated numerically by the RSM-CCRD were $5.34 \mathrm{~h}$ of time, $11.25 \%$ of (NH4)2SO4 concentration, $25.16 \mathrm{ml}$ of concentrated $\mathrm{H} 2 \mathrm{SO} 4$ and $151.15^{\circ} \mathrm{C}$ of temperature which gave $93.30 \%$ FFA conversion and yield of $91.87 \%$ FAME. The optimum sulfonated catalyst was characterized using X-ray diffraction (XRD), fourier transform infrared (FTIR), thermogravimetric analyser (TGA), Brunauer Emmett Teller (BET), temperature programmed ammonia desorption (TPD-NH3), and field emission scanning electron microscope (FESEM) to establish its properties. The optimized sulfonated catalyst was further used for esterification to optimize the process conditions. The optimized catalyst had a BET surface of $4.47 \mathrm{~m} 2 / \mathrm{g}$ and acid site density (Brønsted) of $5.92 \mathrm{mmol} / \mathrm{g}$ exhibited high catalytic activity as a result of efficient accessibility of PFAD and methanol to the sulfonic sites during the esterification reaction. The optimization of the esterification process conditions achieved $93.23 \%$ FFA conversion at optimum process conditions of $4 \mathrm{wt} \%$ of optimized sulfonated catalyst, 10:1 methanol to PFAD molar ratio, $65{ }^{\circ} \mathrm{C}$ temperature and $4 \mathrm{~h}$ of reaction time. The synthesized catalyst showed it could be reused up to five cycles maintaining a high catalytic activity. Therefore, the catalyst has proved to be a potential heterogeneous candidate for the conversion of high acid value feedstock.
\end{abstract}

Keyword: Sulfonated glucose acid catalyst; Optimization; Esterification; Palm fatty acid distillate; Biodiesel 